\title{
Case Report \\ Torsion of Testis in an Infant with Unilateral UDT
}

\author{
Mohammad Kazem Moslemi, ${ }^{1}$ Mehdi Abedinzadeh, ${ }^{2}$ and Shabir Al-Mousawi ${ }^{3}$ \\ ${ }^{1}$ Department of Urology, Kamkar Hospital, School of Medicine, Qom University of Medical Science, Qom 3715694978, Iran \\ ${ }^{2}$ Department of Urology, Moradi Hospital, School of Medicine, Rafsanjan University of Medical Sciences, \\ 3715694969 Rafsanjan, Iran \\ ${ }^{3}$ Division of Urology, Department of Surgery, Al-Amiri Hospital, 13041 Kuwait City, Kuwait
}

Correspondence should be addressed to Mehdi Abedinzadeh, abedinoro@yahoo.com

Received 31 August 2010; Accepted 12 October 2010

Academic Editor: Frans J. Walther

Copyright (C) 2010 Mohammad Kazem Moslemi et al. This is an open access article distributed under the Creative Commons Attribution License, which permits unrestricted use, distribution, and reproduction in any medium, provided the original work is properly cited.

\begin{abstract}
Torsion of an undescended testis is uncommon. Torsion of a cryptorchid testicle presents a nonspecific symptomatology. Clinical suspicion indicates emergent surgical exploration, irrespective of Doppler ultrasound with its inherent false negative results. Management of the contralateral testis is controversial. We emphasize the need of a complete physical examination of the child who goes to the emergency room with nonspecific symptoms of abdominal pain and ipsilateral empty hemiscrotum to rule out torsion of a cryptorchid testicle. Herein, we report a one-year-old infant with missed torsion of undescended left testis.
\end{abstract}

\section{Case Presentation}

The patient was a one-year-old infant that presented with 3-day history of poor feeding, restlessness, progressive left inguinal swelling, and tenderness. In physical examination, a swollen left inguinal area with redness, point tenderness, and ipsilateral empty hemiscrotum was noted. The parents noted that they had been informed about the presence of a left UDT in their infant 3 months before. In the sonographic evaluation of testes, the right testis was normal, but the inguinal left testis was edematous, and no testicular circulation was found in Doppler evaluation of it. The patient underwent surgical exploration with left inguinal incision under the diagnosis of missed testicular torsion. After opening of layers, necrotic deep extravaginal testicular torsion that was located at the deep inguinal area was noted (Figure 1). Due to the complete necrosis of testicle, orchiectomy was performed (Figures 2 and 3). Surgical orchiopexy of the right side was postponed, because it was in normal position, and there is a risk of compromising its circulation due to manipulation or impending infection or parenchymal injury.

\section{Discussion}

Cryptorchidism constitutes a common congenital surgical problem encountered in males in pediatric urology. The incidence of cryptorchidism or maldescended testis in fullterm neonates is estimated to be from $2.7 \%$ to $5.9 \%$ at birth, but decreases to $1.2 \%$ or $1.8 \%$ by age 1 year [1]. The literature concerning undescended testis mainly concentrates on the increased risks of infertility and germ cell development as the primary sequel of this condition [2]. Yet, the UDT also appears to be at higher risk for torsion compared to the normally descended testis. Torsion of the spermatic cord was first described by Delasiauve in 1840, and interestingly, it was in a 15-year-old boy with the UDT treated with orchiectomy [3]. Williamson estimated torsion to be approximately 10 times more common in cryptorchidism [4]. Still, this issue is currently poorly addressed and sometimes neglected even in contemporary articles concerning pediatric testicular problems [1]. The mechanism of torsion in the undescended testis is not well understood. It has been postulated that it is related to a greater relative broadness of the testis compared to its mesentery [5], which is a possible explanation for the 


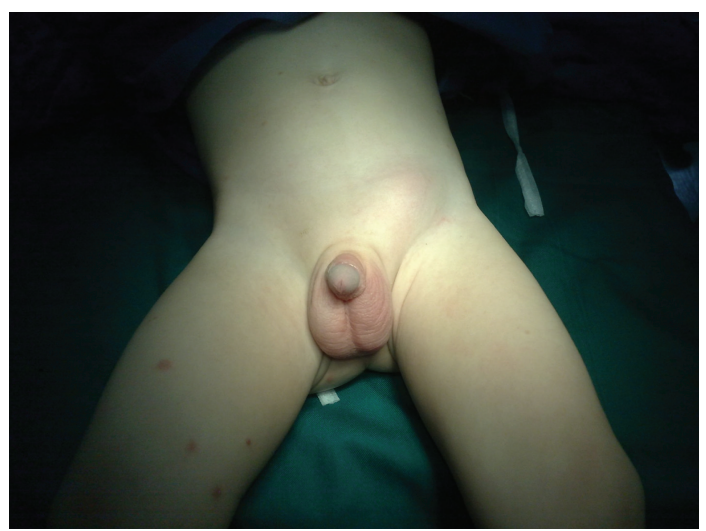

Figure 1: Swollen left inguinal area is evident.

reported association with testicular tumors [6, 7]. Another theory involving abnormal contractions of the cremasteric muscles, which are responsible for the spermatic twist [8]. The diagnosis of torsion of an undescended testis should be considered in every child presenting with unexplained groin or abdominal pain in the presence of tender groin, swelling, and an empty ipsilateral hemiscrotum [5, 7]. Not unexpectedly, there is not enough awareness among physicians or parents with regard to this urological emergency, and in most cases, the diagnosis unfortunately is deferred. Testicular torsion (TT) accounts for only about 25\% of all cases of acute scrotum in children [9], but requires prompt diagnosis and treatment in order to avoid ischemic necrosis of the testis. Some of the other differential diagnoses of acute scrotum in children's group are incarcerated hernia, torsion of testicular appendages, epididymoorchitis and trauma. Clinical problems and medicolegal issues are not limited to the preoperative diagnosis of testicular torsion (TT) — in normal descended or cryptorchid testis. In many cases, during exploration, the clinician faces the dilemma of whether to remove a testicle whose viability seems questionable and, in the absence of objective criteria, can only rely upon their own empirical experience [10]. Duration of symptoms before surgery is a well-known predictor of outcome in TT [11]. Another somewhat controversial point is whether prophylactic fixation of the contralateral testis is indicated $[3,8,12]$. While the reported salvage rate in testicular torsion ranges from $20 \%$ to $92 \%[8,12]$, there are no such data available concerning undescended testis.

\section{Conclusion}

Torsion of an undescended testis is a relatively rare phenomenon that should be suspected, diagnosed, and treated without delay. With improved recognition of this entity and earlier referrals of patients with undescended testes by primary care physicians, this entity might eventually be prevented. As for the diagnosis of torsion in normal descended testis, there is no one history, physical, laboratory, or radiological finding that might predict testicular salvageability. This can only be determined at surgical exploration

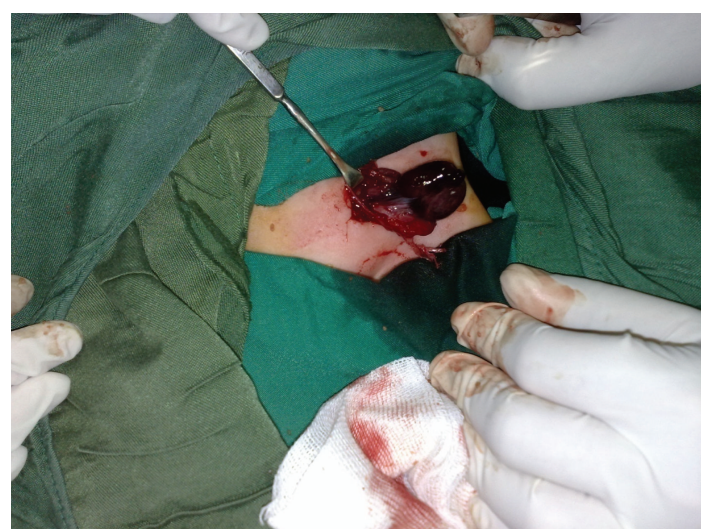

FIGURE 2: Necrotic testis with its overlying layers.

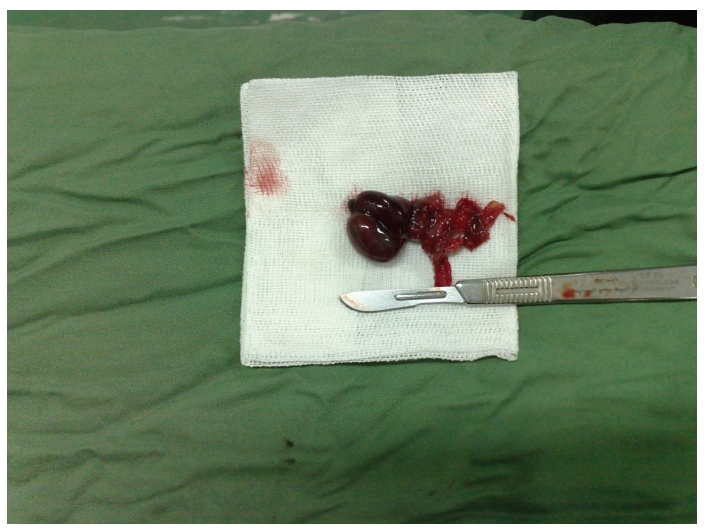

Figure 3: Removed necrosed testicle.

and is independent of the degree of torsion. In addition, when it is remembered that close to $2 \%$ of all males have an undescended testis, the risk of torsion in an undescended testis clearly needs to be made more evident to pediatric urologists and pediatricians.

\section{Consent}

Written consent was obtained from the patients parents for publication of this paper and for use of images in it. A copy of the written consent is available.

\section{Competing Interests}

The authors declare that they have no competing interests.

\section{Authors Contributions}

M. K. Moslemi was the responsible surgeon, and M. Abedinzadeh and S. Al-Mousawi prepared and edited the paper. 


\section{References}

[1] S. B. Pillai and G. E. Besner, "Pediatric testicular problems," Pediatric Clinics of North America, vol. 45, no. 4, pp. 813-830, 1998.

[2] P. A. Lee, "Fertility after cryptorchidism: epidemiology and other outcome studies," Urology, vol. 66, no. 2, pp. 427-431, 2005.

[3] K. E. Schultz and J. Walker, "Testicular torsion in undescended testes," Annals of Emergency Medicine, vol. 13, no. 7, pp. 567$569,1984$.

[4] R. C. N. Williamson, "Torsion of the testis and allied conditions," British Journal of Surgery, vol. 63, no. 6, pp. 465476, 1976.

[5] F. X. Schneck and M. F. Bellinger, "Abnormalities of the testis and scrotum and their surgical management," in Campbells Urology, P. C. Walsh, A. B. Retik, E. D. Vaughan Jr., and A. J. Wein, Eds., chapter 67, pp. 2353-2394, WB Saunders, Philadelphia, Pa, USA, 8th edition, 2002.

[6] H. C. Rigler, "Torsion of intraabdominal testes," Surgical Clinics of North America, vol. 52, p. 371, 1972.

[7] J. H. Johnson, "Abnormalities of the scrtum and the testes," in Paediatric Urology, D. I. Williams, Ed., chapter 37, pp. 451465, Butterworth Scientific, London, UK, 2nd edition, 1982.

[8] F. J. Candocia and K. Sack-Solomon, "An infant with testicular torsion in the inguinal canal," Pediatric Radiology, vol. 33, no. 10, pp. 722-724, 2003.

[9] A. A. Caldamone, J. R. Valvo, V. K. Altebarmakian, and R. Rabinowitz, "Acute scrotal swelling in children," Journal of Pediatric Surgery, vol. 19, no. 5, pp. 581-584, 1984.

[10] M. Cimador, M. R. DiPace, M. Castagnetti, and E. DeGrazia, "Predictors of testicular viability in testicular torsion," Journal of Pediatric Urology, vol. 3, no. 5, pp. 387-390, 2007.

[11] A. E. Sessions, R. Rabinowitz, W. C. Hulbert, M. M. Goldstein, and R. A. Mevorach, "Testicular torsion: direction, degree, duration and disinformation," Journal of Urology, vol. 169, no. 2, pp. 663-665, 2003.

[12] C. A. Sheldon, "Undescended testis and testicular torsion," Surgical Clinics of North America, vol. 65, no. 5, pp. 1303-1329, 1985. 


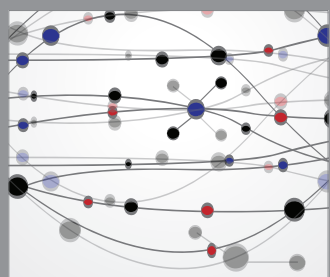

The Scientific World Journal
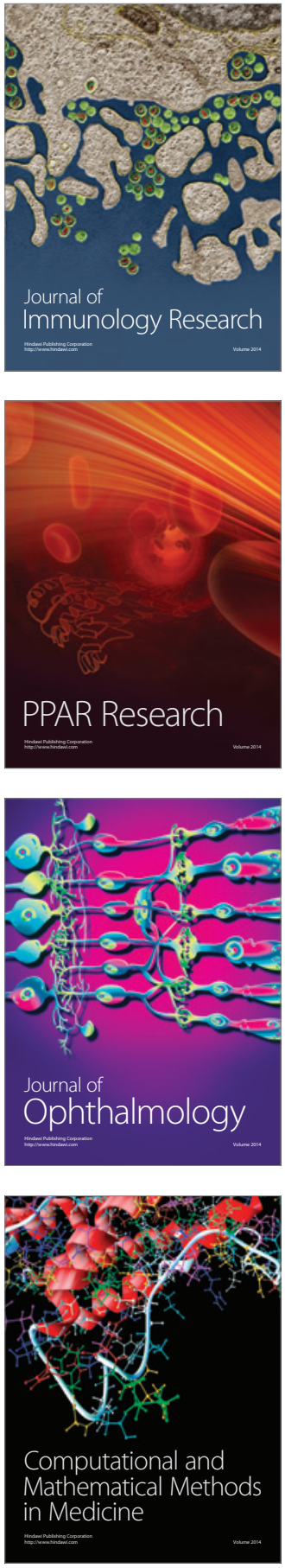

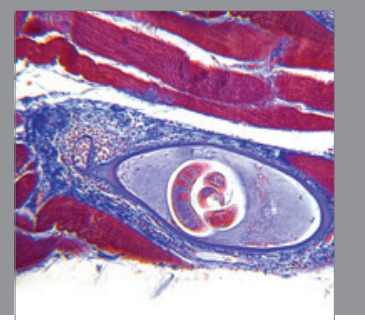

Gastroenterology

Research and Practice
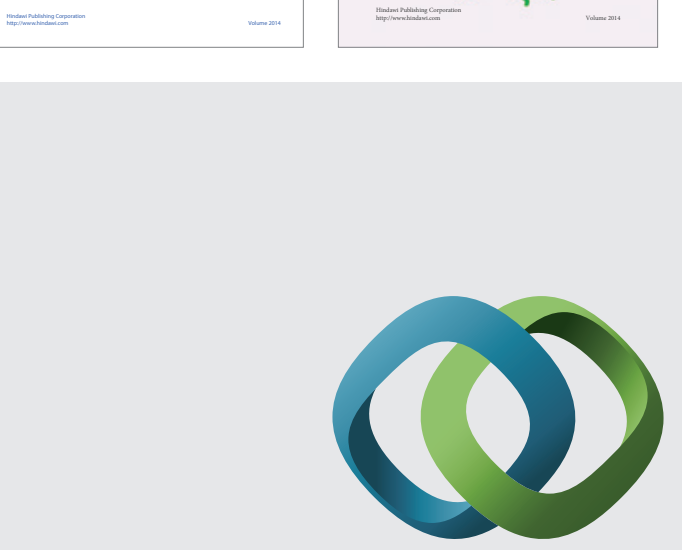

\section{Hindawi}

Submit your manuscripts at

http://www.hindawi.com
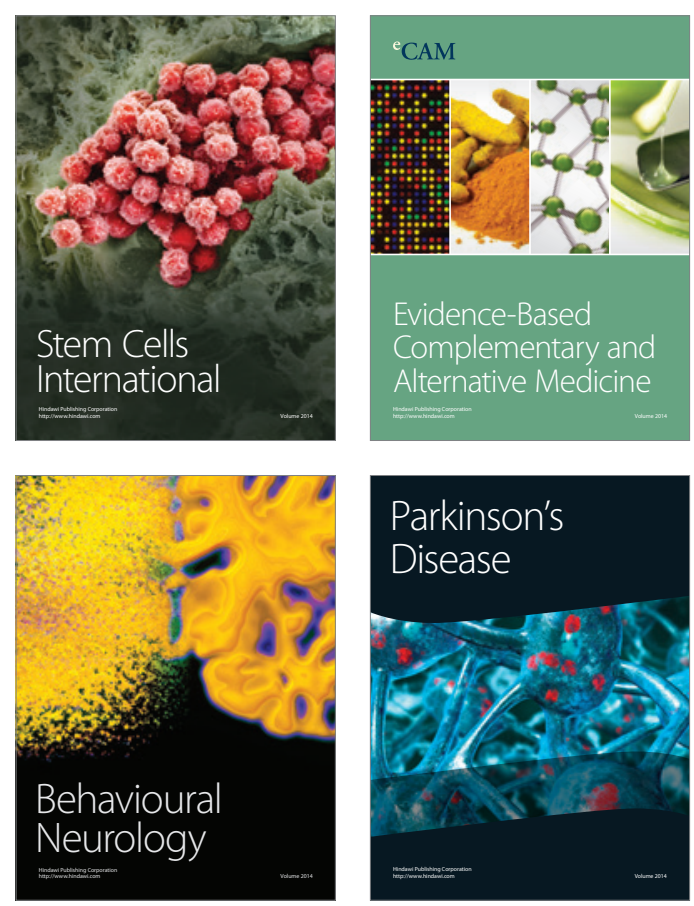

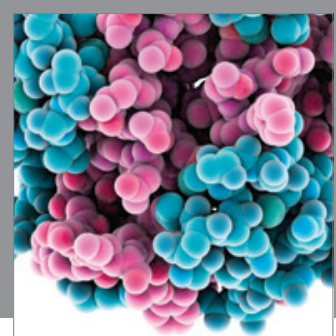

Journal of
Diabetes Research

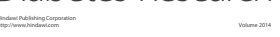

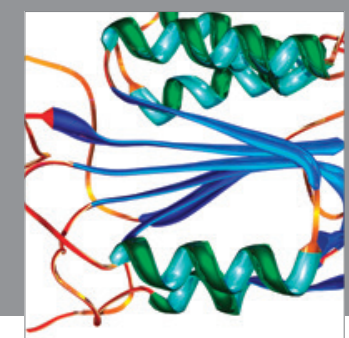

Disease Markers
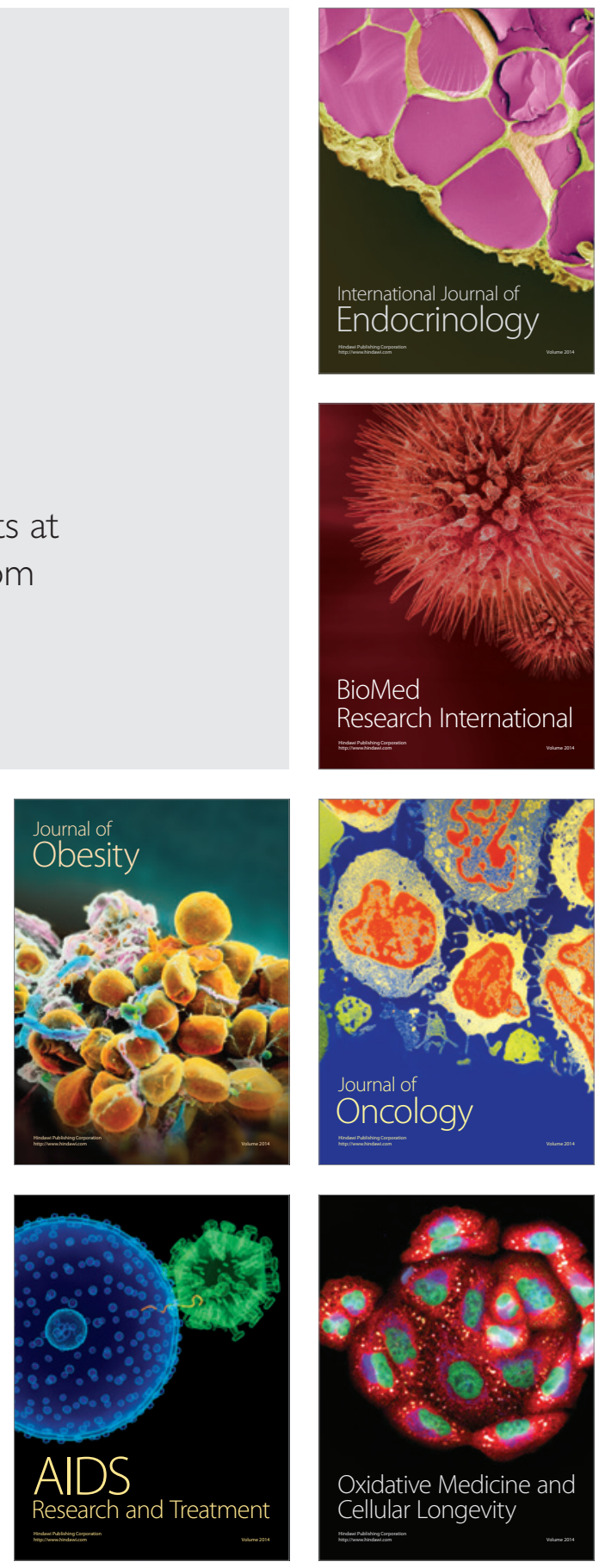